\title{
GIS-based spatial zoning for flood inundation modelling in the Murray-Darling Basin
}

\author{
C. Huang ${ }^{a, b}, \underline{\text { Y. Chen }}{ }^{b}$ and J. Wu ${ }^{\text {a }}$ \\ ${ }^{a}$ Key Laboratory of Geographic Information Science, East China Normal University, \\ Shanghai, 2000241, China \\ ${ }^{b}$ Land and Water CSIRO, Canberra 2601, Australia \\ Email: chang.huang@outlook.com
}

\begin{abstract}
Flood inundation modelling for ecological purpose is important for the Murray-Darling Basin (MDB). It is necessary to divide the basin into hydrologically similar but ecologically independent zones due to its complex topological and hydrological conditions. Pioneer studies in zone delineation at large basin scale have been proven to be successful. However, an outstanding issue identified in these studies is that the topography and hydrological connectivity have not been given enough consideration, which results in the lack of explicit spatial connectivity between zones.

In this study, the Australian Hydrological Geospatial Fabric (Geofabric) published by the Bureau of Meteorology of Australia was employed to classify the MDB into eco-hydrological zones. The Geofabric is based on a variety of topological data and has a consistent representation of hydrological features and their connectivity, which are crucial for spatial zoning. Several zoning criteria were established taking into consideration the gauge location, flow data quality and availability, and landscape integrity. Based on these criteria, a number of neighbouring catchments in the Geofabric were combined to generate an ecohydrological zone. A representative gauge was selected for each zone to best reflect the flow that goes through it. All zones are spatially and hydrologically connected via a stream network. Improved relationships between flow and inundation, and spatial pattern of inundation extent have been achieved compared to the existing zones. It is hoped that the derived zones will be able to help develop floodplain inundation models that can be easily integrated into the Geofabric-based geospatial framework.
\end{abstract}

Keywords: $\quad$ hydrological spatial zoning, flood inundation modelling, gauge flow, Geofabric 


\section{INTRODUCTION}

River floodplain inundation plays a crucial role in maintaining riparian ecosystems. Modelling inundation, therefore, is essential for understanding hydrological and ecological processes in these ecosystems. Temporal and spatial changes in flood inundation extent are complex for large river basins, such as the Murray-Darling Basin (MDB), where hydro-ecological characteristics vary significantly across the basin. The spatio-temporal pattern of flood inundation is usually unpredictable and ecological responses are hard to analyze. A simple solution for this is dividing the region into smaller zones which have hydrological similarity and ecological independence, so called eco-hydrological zones.

The development of the eco-hydrological zones is a trade-off between the finer resolution of the river and floodplain behavior, the reality of available river gauges, and a reasonable number of reporting zones (Overton 2009). The collection of streamflow data that are both accurate and representative of a region's water resource is essential. Surface water gauging stations are monitoring tools used to measure flow rate in streams and rivers. Remote sensing provides an efficient way of detecting flood inundation extent over large areas (Chen et al. 2013; Huang et al. 2013a). For a better understanding of the surface water dynamic, it is necessary to connect each zone with a representative gauge if applicable.

The Murray-Darling Basin Flood Inundation Modelling (MDB-FIM) projects (Overton et al. 2011; Chen et al. 2012) were a zoning of MDB for flood inundation modelling at whole-of-basin scale. Flood inundation pattern was modeled by linking gauge flow with inundation detected from remotely sensed imagery. More than 90 zones were delineated in these projects. These zones were used in the development of a basin-wide floodplain inundation model and have proven to be very helpful in that region (Chen et al. 2011; Huang et al. 2012; Huang et al. 2013b). The zoning process links floodplain inundation areas to their associated rivers directly and reduces time-lag between flow and inundation. However, as these zones were not produced in associated with elevation data, most of the zone boundaries are inconsistent with terrain ridges. This may cause incorrect inundation patterns in some areas. Some important wetlands in the MDB are split by zones, which lowers the ecological significance of flood inundation pattern in these wetlands. Most importantly, the topography and hydrological connectivity have not been given enough consideration, which results in the lack of explicit spatial connectivity between zones. Therefore, it is necessary to develop a new method for zoning that takes the topography into consideration and achieves more explicit spatial connectivity between zones.

Several studies (Dingman 1977; Potemkina 2004; Holmes and Goebel 2011; Fernandez et al. 2012) have tried to delineate riparian or floodplain zones using hydrological and topographic data. However, spatial connectivity is not implementable without additional information. The Geofabric (BOM 2013), which is intended to underpin the Australian Water Resources Information System (AWRIS), provides multi-scale hydrological units over the Australian continent. It is based on a variety of topological data and has a consistent representation of water features and their connectivity in the Australian water system. This study aims to subdivide the MDB into smaller reporting zones to provide a basis for assessing regional floodplain inundation patterns against river flows for the purpose of floodplain inundation mapping. It employs Geofabric products to classify the MDB into eco-hydrological zones on the basis of existing MDB-FIM zones. The resultant zones will be spatially connected by the river network. Ideally, for each zone, there will be a representative gauge measuring the water volume that flows through it. The result of this study will be able to provide a comprehensive basis for floodplain inundation modeling at large river basin scale.

\section{STUDY AREA AND MATERIALS}

\subsection{Study area}

As Australia's most important agricultural region, the MDB produces one third of Australia's food supply and supports over a third of Australia's total gross value of agricultural production. It is Australia's largest and most environmentally, economically and culturally significant basin. It has a catchment area of approximately $1,061,000 \mathrm{~km} 2$, equivalent to $14 \%$ of the country's total area (Discover Murray 2013). It extends over threequarters of New South Wales (NSW), more than half of Victoria, significant portions of Queensland (QLD) and South Australia (SA). Well over half of the Basin is in NSW and almost a quarter is in QLD (Figure 1). There are three major rivers in the MDB, the Murray River, the Darling River and the Murrumbidgee River. Most rivers in the basin run from temperate uplands on the southern and eastern margins, and drain inland towards increasingly low elevation and low relief, semiarid to arid depositional settings (Thoms and Sheldon 2000; Ward et al. 2002). The basin includes 17 large and complex floodplain wetland systems which are associated with relatively large perennial or intermittent rivers (Rogers and Ralph 2010). The wetlands in the MDB are important for many water dependent ecosystems, which requires specific seasonal and inter-year flooding regimes to maintain ecological function. 


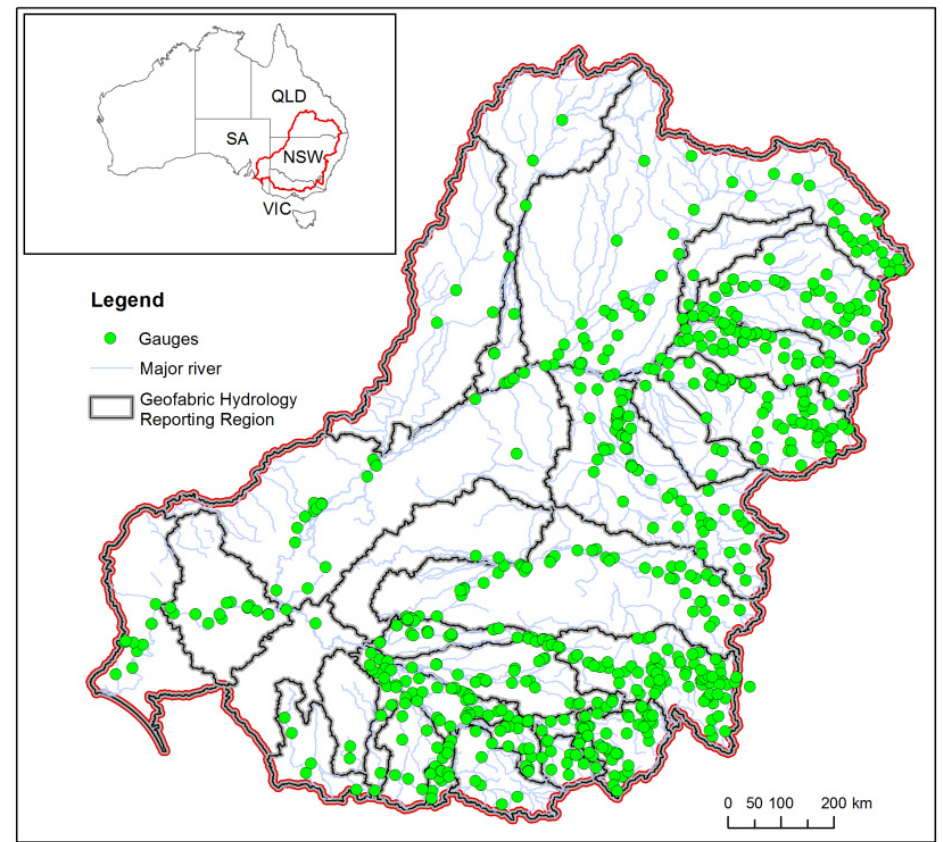

Figure1. Geofabric Hydrology Reporting Regions, observed gauges and major rivers within the Murray-Darling Basin

\subsection{Geofabric}

The Geofabric is a suite of authoritative spatial data products forming a national geospatial framework for hydrological features. It registers the spatial relationships between important hydrological features such as rivers, water bodies, aquifers and monitoring points. The Geofabric is based on key national datasets including (BOM 2011):

- National hydrography layer (AusHydro1) at 1:250,000 with topological connectivity and directional flow paths

- New set of national catchment boundaries derived from a 9-second Digital Elevation Model (DEM)

- New national DEM at 1-second resolution derived from the Shuttle Radar Topography Mission (SRTM) data

The Geofabric products consist of six distinct but related geospatial datasets. They are listed in Table 1. In this study, only Geofabric Surface Network, Geofabric Surface Catchments and Geofabric Hydrology Reporting Regions (shown as Figure 1) were used.

Table 1. Geofabric products

\begin{tabular}{|l|l|l|}
\hline \multicolumn{1}{|c|}{ Name } & \multicolumn{1}{c|}{ Product } & \multicolumn{1}{c|}{ Description } \\
\hline SH_Cartography & Geofabric Surface Cartography & $\begin{array}{l}\text { Cartographic representation of hydrological } \\
\text { features }\end{array}$ \\
\hline SH_Network & Geofabric Surface Network & $\begin{array}{l}\text { Network representation of hydrological } \\
\text { features }\end{array}$ \\
\hline SH_Catchment & Geofabric Surface Catchments & $\begin{array}{l}\text { Stream segment catchments derived from } \\
\text { DEM-9s organised into a hierarchy using } \\
\text { the Pfafstetter reference system }\end{array}$ \\
\hline GW_Cartography & & $\begin{array}{l}\text { Groundwater boundaries derived from } \\
\text { Interim Ground Water data }\end{array}$ \\
\hline HR_Catchments & Geofabric Groundwater Cartography & $\begin{array}{l}\text { Contracted catchments hierarchy resulting } \\
\text { from contracted nodes of important } \\
\text { hydrological features }\end{array}$ \\
\hline HR_Regions & Geofabric Hydrology Reporting Catchments & $\begin{array}{l}\text { Drainage division and river region reporting } \\
\text { units, based on contracted catchments }\end{array}$ \\
\hline
\end{tabular}




\subsection{Observed streamflow}

The Murray-Darling Basin Authority (MDBA), through the partner governments, operates and maintains a network of remote hydrometric monitoring stations (MDBA 2013). However, hydrometric data provided by MDBA only focus on key parts of the River Murray system. Data from other gauging sites and other parts of the Basin were obtained from the following agencies and government services:

- New South Wales Office of Water

(http://realtimedata.water.nsw.gov.au/water.stm?ppbm=DAILY_REPORTS\&dr\&3\&drkd_url)

- Queensland Department of Natural Resources and Mines

(http://watermonitoring.derm.qld.gov.au/host.htm)

- South Australian Department of Environment, Water and Natural Resources (https://www.waterconnect.sa.gov.au/RMWD/Pages/default.aspx)

- Victoria Department of Environment and Primary Industries

(http://www.vicwaterdata.net/vicwaterdata/home.aspx)

There are over 700 gauges distributed over the MDB. Their locations are shown in Figure 1.

\section{METHODS}

The Geofabric Hydrology Reporting Regions were used to begin the zoning process. The boundaries of the 28 reporting regions are shown in Figure 1. These boundaries were developed for use in regional scale reporting and hydrological modelling. Geofabric Surface Catchments were used as the basic component of zones. There are about 173,000 catchments within the MDB. The Geofabric Surface Network was employed as basic data for zoning, because it provided important information on the pattern of flood water movement. Spatial connectivity of catchments can be identified from this network via Geofabric.

Several criteria were established to spatially delineate zones within each reporting region of Geofabric.

- Gauge location

Gauge location is an important indicator for zoning. It defines where the recorded flow comes from. Only gauges on the major river channels were used in order to avoid over-zoning into too many small fragments.

- Availability and quality of flow data

Many gauges are multi-purpose monitoring gauges. A gauge may measure surface water, water quality and meteorological parameters at one location. Since we focus on the flood inundation, we need flow rate data. Those gauges that have no flow rate data were thus not used in this study. Some gauges may have been decommissioned and thus cannot provide latest flow data. They were also excluded in this study. Time series of flow rate is important for temporal analysis. Therefore, gauges with long-to-medium record length were more preferred.

- Landscape integrity

Each of the important wetlands will be included in a single zone.

The zoning process progresses from upstream to downstream. The gauge locations were snapped to a nearby and representative network node of Geofabric network. The upstream accumulation of this node was identified using the Utility Network Analyst tool in ArcGIS. The accumulation was considered as an initial zone for the related gauge. This process was conducted for each gauge, bearing in mind the aforementioned criteria. Finally, we derived a number of zones, each with its associated gauges.

\section{RESULT AND DISCUSSION}

Figure 2 shows the 90 zones that were developed for floodplain inundation modelling. Some of the zones have no clear linkage between the major river in the MDB and flood inundation. These zones were displayed as ungauged zones (shaded zones in Figure 2). Some zones require a combination of gauges, such as the combination of upstream gauges on the tributaries. 


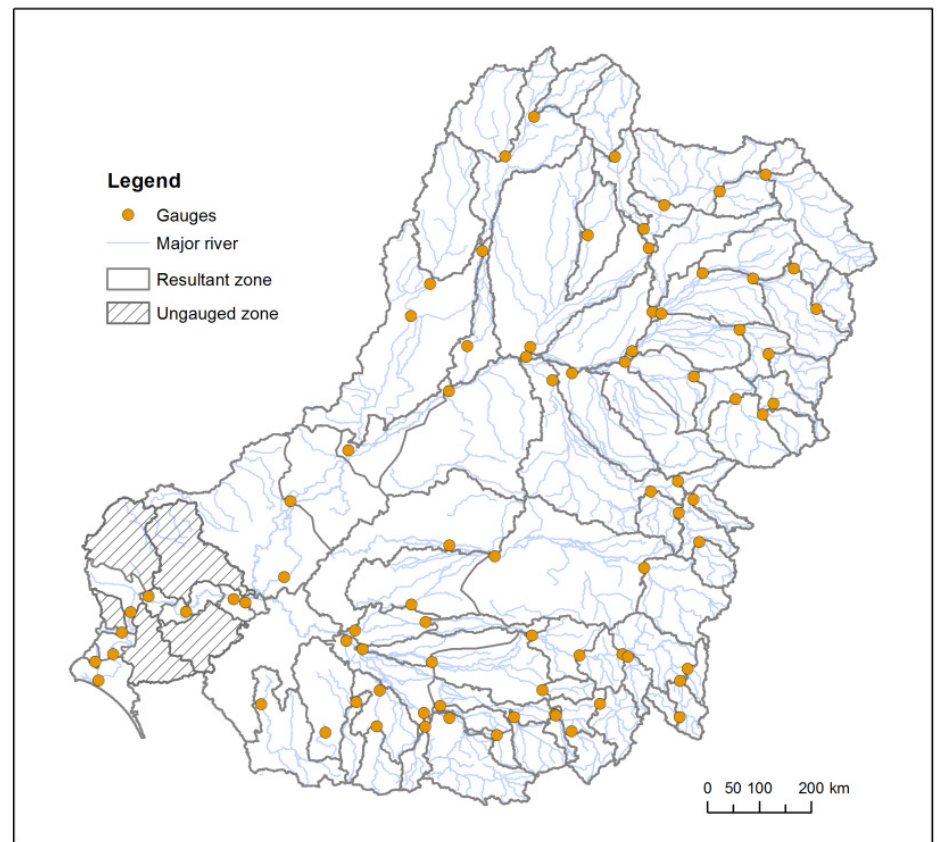

Figure 2. Resultant zones with their representative gauges

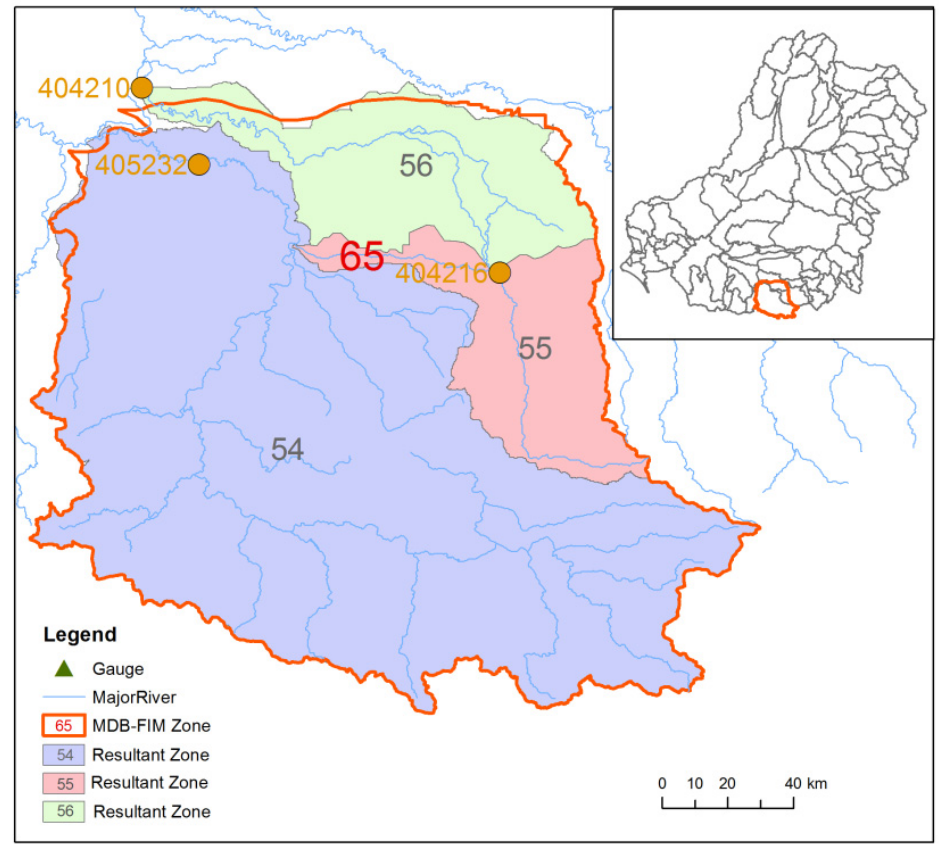

Figure 3. Comparison of a MDB-FIM zones and corresponding resultant zones

In comparison with the previously defined MDB-FIM zones, resultant zones derived in this study are more hydrologically similar. Their boundaries are generally aligned with the boundaries of catchments determined in the Geofabric. Moreover, the flow rate recorded by the selected gauge can better represent the water that flow through its associated zone. Take Zone 65 in the MDBFIM (Figure 3) for example; its related gauge is Gauge 405232. In this study, it was divided into three zones (Zone 54, Zone 55 and Zone 56), which are associated with Gauge 405232, Gauge 404216 and Gauge 404210, respectively. The hydrographs (from 1977 to 2012) of these three gauges are shown as Figure 4. A peak flow of 22.7GL/day was observed at Gauge 404216 on 10/12/2010. Gauge 405232 and Gauge 404210 also experienced a flow peak of 54.8GL/day and 6.7 GL/day in that period (on 14/12/2010 and 24/12/2010 respectively), as shown in the enlarged hydrograph in Figure 4. According to the modelling method in the MDB-FIM (Overton et al. 2011; Chen et al. 2012), Zone 56 in Figure 
3 will have the same inundation extent reflected by remote sensing imagery. Based on the time series flow data of these three gauges, Average Recurrence Intervals (ARIs) were calculated using the River Analysis Package (RAP; eWater 2013) (Figure 5). A peak flow of $6.7 \mathrm{GL} /$ day at Gauge 404210 is a flow peak higher than a 1-in20 flow (3.5 GL/day as shown in Figure 5), whereas the peak $54.8 \mathrm{GL} /$ day for Gauge 405232 is lower than a 1in-10 flow (65.2 GL/day as shown in Figure 5). Therefore, the same inundation extent may have different ecohydrological meanings when using different gauges. From Figure 3, it is clear that Gauge 404210 better represents the water that flows through Zone 56.

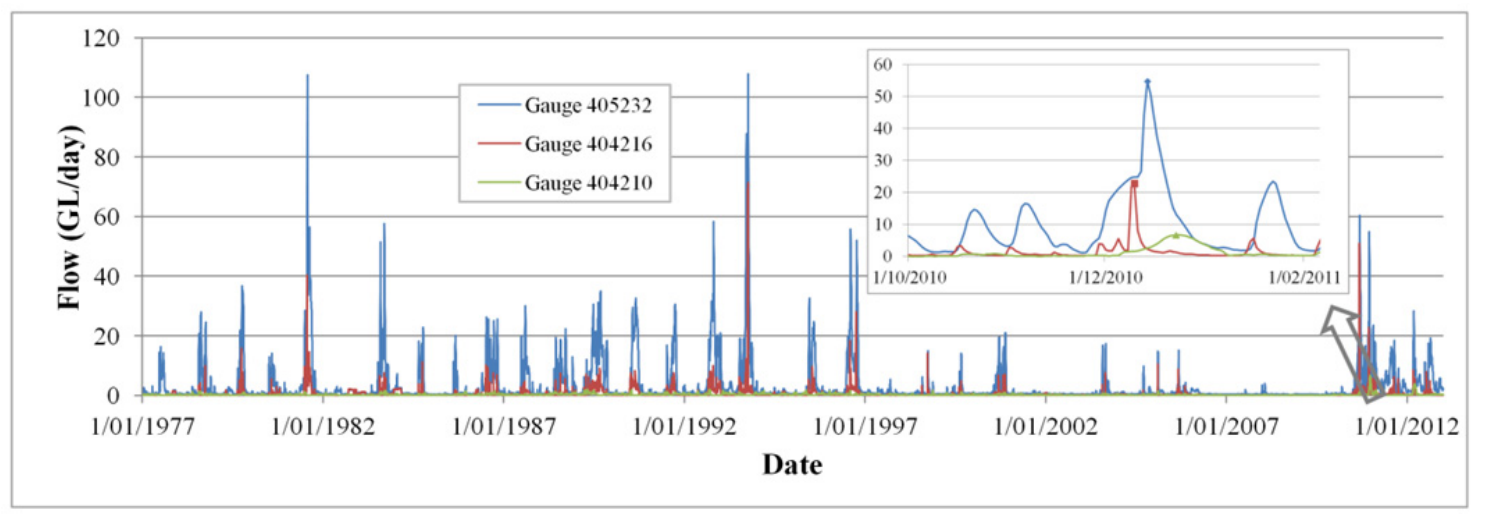

Figure 4. Daily flow rate of Gauge 405232, 404216 and 404210

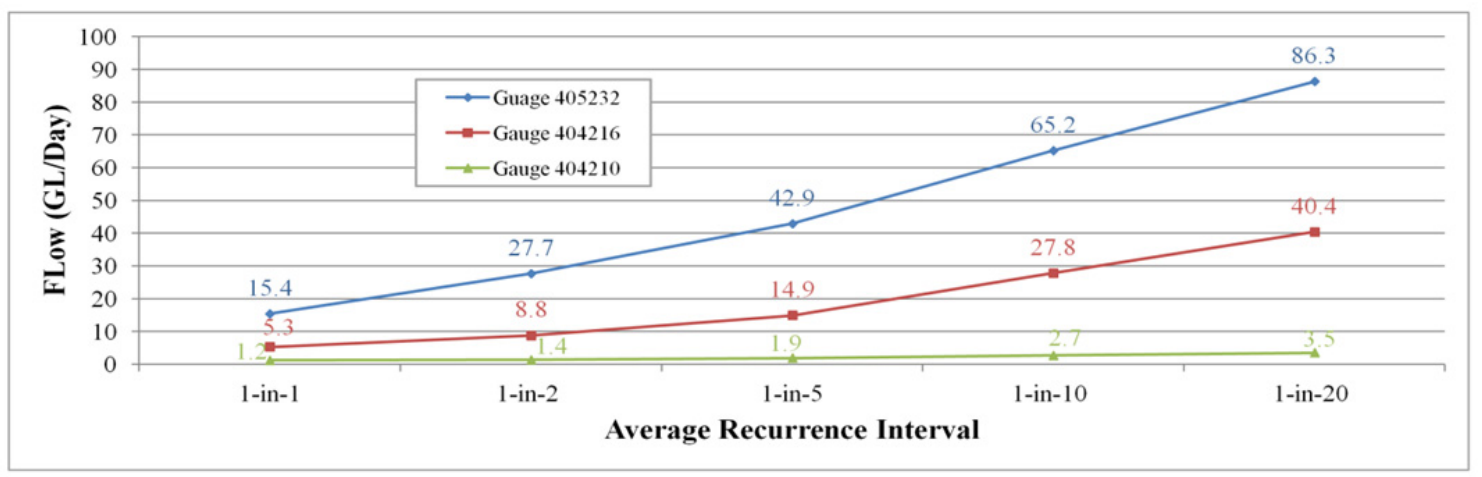

Figure 5. Average Recurrence Intervals for Gauge 405232, 404216 and 404210

Since the zones are derived within the framework of the Geofabric, the spatial connectivity between zones is easily achieved, on the basis of the stream network. The gauges associated with these zones are also connected by the stream network. Therefore, the travel time of stream flow between gauges can be predicted, which is helpful for better estimating the time-lags between flow and inundation, and also for estimating flood durations. This will result in a much closer relationship between time series of gauge flow data and remotely sensed inundation extent.

\section{CONCLUSION}

Spatial zoning is helpful for reporting spatial inundation patterns and monitoring changes to these patterns over time in the MDB. It is also useful for assessing the response of wetland ecosystems to different eco-hydrological conditions. This study employs Geofabric products to divide the whole basin into 90 zones. These zones are spatially and hydrologically connected through the stream network. Their boundaries are consistent with catchment topography. In comparison with the zones derived in the previous MDB-FIM, they are demonstrated to be more reasonable, in terms of the relationships between gauges and zones. As the Geofabric is playing an increasingly important role in constructing the infrastructure network for hydrological researches across the Australian continent, it is hoped that the derived zones will be able to help develop floodplain inundation models that can be easily integrated into the Geofabric-based geospatial framework.

\section{ACKNOWLEDGMENTS}

This work has been conducted under the auspices of the CLW and Water for a Healthy Country National Research Flagship. The authors are grateful to our colleagues, Linda Merrin for her help in collecting gauge data, Dr. Catherine Ticehurst and Tim Smith for initially reviewing this paper. 
Huang et al., GIS-based spatial zoning for flood inundation modelling at large basin scale

\section{REFERENCES}

BOM (2011). Australia Hydrological Geospatial Fabric (Geofabric) Product Guide Version 2.0. Bureau of Meteorology, Australia

BOM (2013). Bureau of Meteorology, Australia. http://www.bom.gov.au/water/geofabric/ (Accessed on 30/04/2013)

Chen, Y., Cuddy, S.M., Merrin, L.E., Huang, C., Pollock, D., Sims, N., Wang, B., Bai, Q. (2012). MurrayDarling Basin Floodplain Inundation Model Version 2.0 (MDB-FIM2). CSIRO Water for a Healthy Country Flagship, Canberra, Australia.

Chen, Y., Cuddy, S.M., Wang, B., Merrin, L.E., Pollock, D., Sims, N. (2011). Linking inundation timing and extent to ecological response models using the Murray-Darling Basin Floodplain Inundation Model (MDBFIM). In: Proceedings of MODSIM2011: The 19th International Congress on Modelling and Simulation: 4092-4098.

Chen, Y., Huang, C., Ticehurst, C., Merrin, L., Thew, P. (2013). An evaluation of MODIS daily and 8-day composite products for floodplain and wetland inundation mapping. Wetlands, 33(5), 823-835. DOI 10.1007/s13157-013-0439-4

Dingman, S.L. (1977). Floodplain zoning: implications of the hydrologic and legal uncertainty. Water Resources Research, 13(3), 519-523.

Discover Murray (2013). Discover Murray River. http://www.murrayriver.com.au/about-the-murray/murraydarling-basin/ (Accessed on 20/02/2013)

eWater (2013). The River Analysis Package. http://www.toolkit.net.au/rap (Accessed on 15/02/2013)

Fernandez, D., Barquin, J., Alvarez-Cabria, M., Penas, F.J. (2012). Quantifying the performance of automated GIS-based geomorphological approaches for riparian zone delineation using digital elevation models. Hydrology and Earth System Sciences, 16, 3851-3862.

Holmes, K.L., Goebel, P.C. (2011). A functional approach to riparian area delineation using geospatial methods. Journal of Forestry, 6, 233-241.

Huang, C., Chen, Y., Wu, J., Yu, J. (2012). Detecting floodplain inundation frequency using MODIS time-series imagery. In: Proceedings of Agro-Geoinformatics2012: The 1st International Conference on AgroGeoinformatics, Shanghai, China.

Huang, C., Chen, Y., Wu, J. (2013a). A DEM-based modified pixel swapping algorithm for floodplain inundation mapping at subpixel scale. In: Proceedings of IGARSS2013: IEEE International Geoscience and Remote Sensing Symposium, Melbourne, Australia.

Huang, C., Chen, Y., Wu, J. (2013b). Mapping spatio-temporal flood inundation dynamics at large river basin scale using time-series flow data and MODIS imagery. International Journal of Applied Earth Observation and Geoinformation, DOI: 10.1016/j.jag.2013.09.002 (In press).

MDBA (2013). Murray-Darling Basin Authority, Australia. http://www.mdba.gov.au/river-data/live-river-data (Accessed on 03/05/2013)

Overton, I.C., Colloff, M.J., Doody, T.M., Henderson, B., Cuddy, S.M. (2009). Ecological Outcomes of Flow Regimes in the Murray-Darling Basin. Water for a Healthy Country Flagship, CSIRO, Adelaide, Australia.

Overton, I.C., Doody, T.M., Chen, Y., Pollock, D., Sims, N. (2011). Murray-Darling Basin Floodplain Inundation Model (MDB-FIM). Water for a Healthy Country Flagship, CSIRO, Adelaide, Australia.

Potemkina, T.G. (2004). Hydrological-morphological zoning of the mouth zone of the Selenga River. Water Resources, 31(1), 11-16.

Rogers, K., Ralph, J.T. (2010). Floodplain Wetland Biota in the Murray-Darling Basin: Water and Habitat Requirements. Collingwood, Victoria, Australia

Thoms, M.C., Sheldon, F. (2000). Water resource development and hydrological change in a large dryland river: the Barwon-Darling River, Australia. Journal of Hydrology, 228, 10-21.

Ward, J.V., Tockner, K., Arscott, D.B., Claret, C. (2002). Riverine landscape diversity. Freshwater Biology, 47, 517-539. 